November 30, 2011

Ms. Terri Kneitel

U.S. Department of Energy

Brookhaven Site Office

53 Bell Avenue, Bldg. 464

Upton, NY 11973

\title{
DOE CONTRACT NO. DE-AC05-06OR23100 \\ SUBJECT: TYPE A VERIFICATION REPORT FOR THE HIGH FLUX BEAM REACTOR STACK AND GROUNDS, BROOKHAVEN NATIONAL LABORATORY, UPTON, NEW YORK DCN: 5098-SR-08-0
}

Dear Ms. Kneitel,

The U.S. Department of Energy (DOE) Order 458.1 requires independent verification (IV) of DOE cleanup projects (DOE 2011). The Oak Ridge Institute for Science and Education (ORISE) has been designated as the responsible organization for IV of the High Flux Beam Reactor (HFBR) Stack and Grounds area at Brookhaven National Laboratory (BNL) in Upton, New York. The IV evaluation may consist of an in-process inspection with document and data reviews (Type A Verification) or a confirmatory survey of the site (Type B Verification). DOE and ORISE determined that a Type A verification of the documents and data for the HFBR Stack and Grounds: Survey Units (SU) 6, 7, and 8 was appropriate based on the initial survey unit classification, the walkover surveys, and the final analytical results provided by the Brookhaven Science Associates (BSA).

The HFBR Stack and Grounds surveys began in December 2010 and were completed in September 2011. Survey activities by BSA included gamma walkover scans and sampling of the as-left soils in accordance with the BSA Work Procedure (BNL 2010a). The Field Sampling Plan - Stack and Remaining HFBR Outside Areas (FSP) stated that gamma walk-over surveys would be conducted with a bare sodium iodide $(\mathrm{NaI})$ detector, and a collimated detector would be used to check areas with elevated count rates to locate the source of the high readings (BNL 2010b). BSA used the Mult- Agency Radiation Survey and Site Investigation Manual (MARSSIM) principles for determining the classifications of each survey unit. Therefore, SUs 6 and 7 were identified as Class 1 and SU 8 was deemed Class 2 (BNL 2010b).

Gamma walkover surveys of SUs 6, 7, and 8 were completed using a $2 \times 2 \mathrm{NaI}$ detector coupled to a data-logger with a global positioning system (GPS). The 100\% scan surveys conducted prior to the final status survey (FSS) sampling identified two general soil areas and two isolated soil locations with elevated radioactivity. The general areas of elevated activity identified were investigated further with a collimated $\mathrm{NaI}$ detector.

The uncollimated average gamma count rate was less than 15,000 counts per minute (cpm) for the SU 6, 7, and 8 composite area (BNL 2011a). Elevated count rates were observed in portions of each survey unit. The general areas of elevated counts near the Building 801 ventilation and operations 
and the entry to the Stack were determined to be directly related to the radioactive processes in those structures. To compensate for this radioactive shine, a collimated or shielded detector was used to lower the background count rate (BNL 2011b and c). This allowed the surveyor(s) to distinguish between background and actual radioactive contamination. Collimated gamma survey count rate in these shine affected areas were below 9,000 cpm (BNL 2011a). The average background count rate of 7,500 cpm was reported by BSA for uncollimated $\mathrm{NaI}$ detectors (BNL 2011d). The average collimated background ranged from 4,500-6,500 cpm in the westernmost part of SU 8 and from 2,000-3,500 cpm in all other areas (BNL 2011e). Based on these data, no further investigations were necessary for these general areas.

SU 8 was the only survey unit that exhibited verified elevated radioactivity levels. The first of two isolated locations of elevated radioactivity had an uncollimated direct measurement of $50,000 \mathrm{cpm}$ with an area background of 7,500 cpm (BNL 2011f). The second small area exhibiting elevated radiation levels was identified at a depth of 6 inches from the surface. The maximum reported count rate of 28,000 cpm was observed during scanning (BNL 2011g). The affected areas were remediated, and the contaminated soils were placed in an intermodal container for disposal.

BSA's post-remediation walkover surveys were expanded to include a 10-foot radius around the excavated locations, and it was determined that further investigation was not required for these areas (BNL $2011 \mathrm{f}$ and $\mathrm{g}$ ). The post-remediation soil samples were collected and analyzed with onsite gamma spectroscopy equipment. These samples were also included with the FSS samples that were analyzed at an offsite facility for the primary radionuclides of concern (ROCs) (i.e., cesium-137, strontium-90, and radium-226). Analysis included full spectrum gamma spectroscopy for all samples. Sr-90 analysis was completed on all samples from SUs 6 and 7. However Sr-90 was only completed on the cores, composites, field blank and duplicate samples in SU 8. Alpha spectroscopy as well as liquid scintillation performed for tritium, carbon-14, and nickel-63 concentrations were completed on the composite samples from SUs 6 and 7. Various cores, composites, and samples from the remediated areas of SU 8 received alpha spectroscopy as well as liquid scintillation analyses for tritium, carbon-14, and nickel-63 to determine respective ROC concentrations (BNL $2011 \mathrm{~h}, \mathrm{i}$, and j).

BSA submitted the FSS data and analytical results to demonstrate that remediation efforts complied with the specified cleanup goal of less than or equal to 15 millirem per year (mrem/yr) above background to a resident in 50 years (BNL 2011a through j). ORISE has reviewed the project documentation and FSS data for the HFBR Stack and Grounds: SUs 6, 7, and 8. The highest concentrations of the primary ROCs reported were 5.92 picocuries per gram $(\mathrm{pCi} / \mathrm{g})$ for Cs-137 and $2.03 \mathrm{pCi} / \mathrm{g}$ for Sr-90, with both ROCs having the qualifier for the sample result as less than the minimum detectable activity (MDA). For Ra-226, the highest detected concentration from the FSS data provided was $0.682 \mathrm{pCi} / \mathrm{g}$. Other potential secondary contaminants were below their respective MDAs. Therefore, ORISE is of the opinion that BSA has provided sufficient evidence to demonstrate compliance with the $15 \mathrm{mrem} / \mathrm{yr}$ cleanup objectives for the final status survey data provided. 
Please contact me via my information provided below, or Phyllis Weaver at (865) 576-5321, should you have any questions or require additional information.

Sincerely,

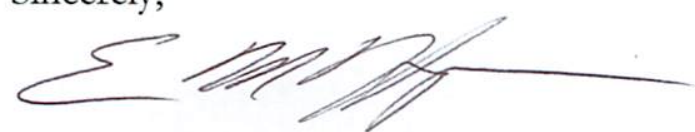

Evan M. Harpenau

Health Physicist/Assistant Project Manager

Independent Environmental Assessment

And Verification

EMH:bj

Enclosure

cc: S. Roberts, ORISE/IEAV

T. Vitkus, ORISE/IEAV

P. Weaver, ORISE/IEAV

E. Bailey, ORISE/IEAV

File/5098

\begin{tabular}{|l|l|}
\hline Distribution approval and concurrence: & Initials \\
\hline Technical Review & \\
\hline
\end{tabular}




\section{TYPE A VERIFICATION REPORT FOR THE HIGH FLUX BEAM REACTOR STACK AND GROUNDS BROOKHAVEN NATIONAL LABORATORY UPTON, NEW YORK \\ REFERENCES}

Brookhaven National Laboratory (BNL). Work Procedure; Final Status Survey (FSS) Procedure for the Building 705 Stack and Remaining HFBR Outside Areas. December 10, 2010a.

Brookhaven National Laboratory. Field Sampling Plan; Building 705 Stack and Remaining HFBR Outside Areas. December 13, 2010b.

Brookhaven National Laboratory. Survey Data; Remaining HFBR Outside Areas SU 6, 7, 8-093011Gamma Walkover, September 30, 2011a.

Brookhaven National Laboratory. Survey Data: Background Data for Gamma Survey in SU 6 and SU 8, July 11, 2011b.

Brookhaven National Laboratory. Survey Data: REM HFBR Grounds SU 7Survey, September 29, 2011c.

Brookhaven National Laboratory. Survey Data: Synopsis for Remediated Areas, November 22, 2011d.

Brookhaven National Laboratory. E-mail from M. Hollander (BNL) to E. Harpenau (ORISE); RE: Surveys for Each SU, November 22, 2011e.

Brookhaven National Laboratory. Survey Data: REM HFBR SU 8 Hotspot Survey, September 29, $2011 \mathrm{f}$.

Brookhaven National Laboratory. Survey Data: REM HFBR SU 8 Hotspot 2 Survey, September 29, 2011g.

Brookhaven National Laboratory. SU 6 GEL Results on COC 31313. November 29, 2011 h.

Brookhaven National Laboratory. SU 7 GEL Results on COC 31313. September 28, 2011 i.

Brookhaven National Laboratory. SU 8 GEL Results on COC 31313. September 30, 2011j.

U.S. Department of Energy (DOE). DOE Order 458.1, Chg 1, Radiation Protection of the Public and the Environment. Washington, DC. March 8, 2011. 